\title{
A New Contract between Business and Business Analysts
}

\author{
Baiba Apine \\ PricewaterhouseCoopers Ltd, \\ Kr. Valdemara str. 21, LV-1010, Riga, Latvia \\ baiba.apine@lv.pwc.com
}

\begin{abstract}
Since the advent of business processes management it has been recognized that its main objective is optimization of enterprise's performance. However, the focus of business analysis has changed significantly over the years. Initially business analysts focused on discovery and modelling of business processes. They aimed to identify opportunities for application of information technologies in business process automation and to determine resources needed for business process execution. More recently, the attention has shifted towards business process monitoring and optimization, while the current trends concern with business process intelligence for agile decisionmaking. Businesses expect that the business analysts will identify opportunities for continuous business process improvement by providing contextualized, high quality and secure information. In the light of these new business expectations, the keynote speech identifies today's challenges faced by the business analysts and describes the current practice in dealing with these challenges.
\end{abstract}

Keywords: Business process, business process modelling, optimisation.

\section{Introduction}

Business process modelling is a very interesting discipline. It does not provide business value per se, however it serves as a backbone for many complex projects and it is a critical factor for completing these projects successfully. Business process reengineering, information system implementation, reorganisation of the company etc. are samples of the projects involving business process modelling as a significant component. The demand for projects involving business process modelling has always been high and will remain so in the future as well. For instance, $64 \%$ of CEOs working for financial institutions have undergone a review and redesign of their organization in the last 12 months [1].

This article summarizes the ten years business modelling experience in Latvia, highlights the major challenges and discusses the latest tendencies faced by the business analysts.

The major challenges faced during the modelling of the business processes are: 1) keeping the model as simple as possible for it to serve as a communication tool among business analyst, technology provider and business; 2) finding balance 
between excellence of the model and cost effectiveness of the modelling process; and 3) dealing with issues of completeness and quality of the model.

While the challenges remain the same, the expectations from business analysts have changed significantly over the years. A decade ago business analysts mostly focused on discovery and modelling of processes aiming to identify opportunities for application of information technologies for process automation and to determine resources needed for business process execution. More recently, the attention has shifted towards business process optimization and business process intelligence for agile decision-making. Businesses expect that the business analysts will identify opportunities for continuous business process improvement by providing contextualized, high quality and secure information as well as have ready-made world class best practices of organizational structures and process templates.

\section{Empirical Data}

The conclusions made in this paper are based on consulting practice at the PricewatehouseCoopers Ltd, Latvia. The company has been involved in the modelling of the business processes for different purposes. The team of $3-4$ business analysts has been constantly working in different projects involving the description of the business processes for 10 years $(2004-2013)$. Totally 90 projects for more than 70 different companies/public sector institutions have been analysed to come up with the conclusions summarized in this article. The split per industries is given in Figure 1.

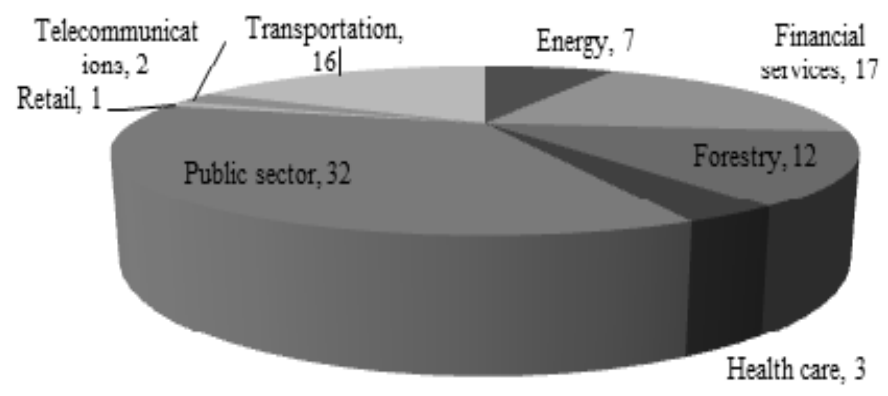

Fig. 1. Business process modelling split per industries (number of projects)

Modified BPMN notation [2] was used for the description of the processes. The average length of the projects was $4-7$ months. All projects were done for companies/public institutions operating in Latvia. Approximately $70 \%$ of the projects involved the description of the 'as-is' processes and 'to-be' processes, while $30 \%$ involved the description of the 'to-be' processes only. For the purposes of the analysis the projects were classified in three groups by the objectives of the business process modelling (see Figure 2). 


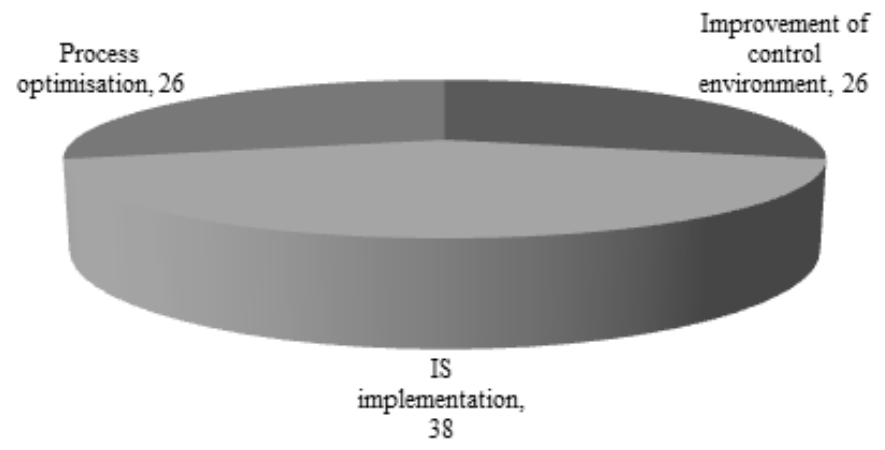

Fig. 2. Purposes of the business process modelling (number of projects)

Business process descriptions for business requirements definition for IS implementation are used (1) to define the requirements for IS implementation; (2) as a source of information about business process for system provider; and (3) to evaluate system providers' proposals for IS implementation; (4) building testing scenarios for IS testing.

Business process description for process optimisation serves (1) for communication of the existing processes among all parties involved in the optimisation and (2) as a source of information for optimisation opportunities for business analysts. Usually these process descriptions include also quantitative information about number of transactions, goods produced, etc.

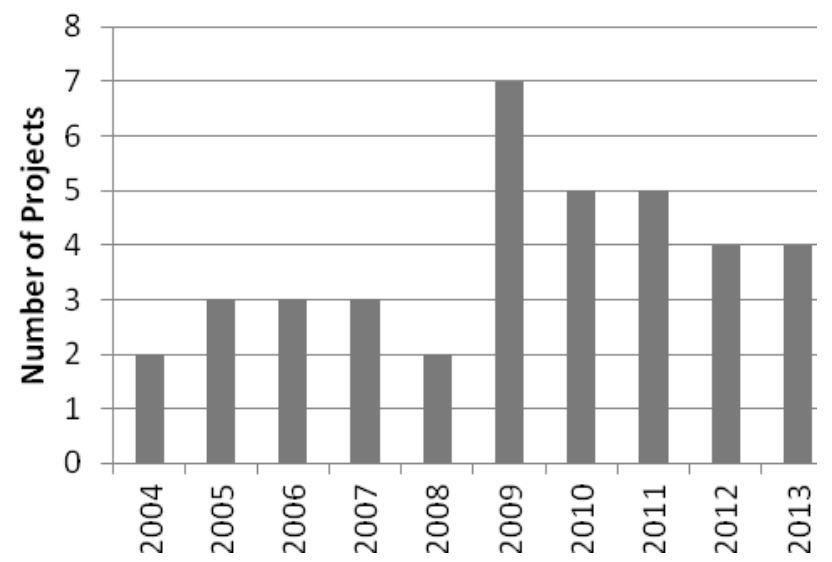

Fig. 3. Number of business process modelling projects per year for information system requirements definition

The business process description for the optimisation of control environment involves (1) identification of control weaknesses against standard/directive/framework 
and (2) strengthening the control environment. However, it is important to keep the business process as effective as possible.

The demand on the business process modelling remains stable since 2004 ( 9 projects annually) with fall in 2008 to 4 engagements due to financial crisis in Latvia (see Figure 3). Business process modelling for information system requirements definition is the most frequent purpose of such projects.

Number of projects involving business process modelling for improvement of control environment is constantly decreasing (from 9 in 2006 to 3 in 2012). The main reason is the cost/benefit from such projects - the cost of building the model is too high to ensure the compliance with regulations only.

Number of projects involving business process description for business process optimisation purposes stays constant as well. However, the number increased during the financial crisis in Latvia (2008 - 2010), when companies were looking for inefficiencies and cost cutting opportunities (see Figure 4).

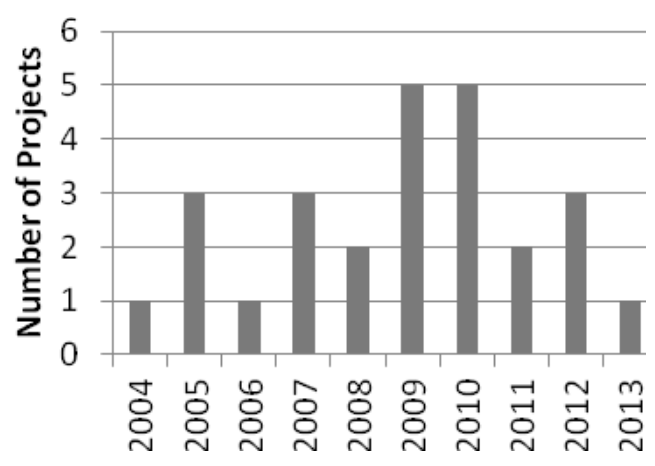

Fig. 4. Number of business process modelling projects per year for optimisation of the business processes

\section{Challenges}

Regardless the overall objective of the projects, the business process modelling is significant part of the whole project. It is one of the most time and resource consuming activities. It is the most complex one and challenging as well. At the same time, the result of the modelling is critical to the success of the project. The team involved in the business process modelling has matured, modelling tools used have changed over the last ten years, however, the challenges faced during the modelling have remained the same.

Regardless the purpose of the business process description, it has to serve as a communication tool among business analyst, business people and sometimes system providers. Hence, the descriptions should be understandable and kept as simple as possible. It is very easy to produce large business models attempting to describe almost all processes in the company. This is the most common mistake for inexperienced business analysts' teams paying much attention to the detail and 
sometimes losing the 'big picture'. Large business models, especially describing existing processes, are very comfortable for business people involved in the processes as they can argue, that processes are too complex to be changed. At the same time it is practically impossible to ensure consistency and understandability of the process descriptions. The descriptions lose their role of the communication tool and the success of the whole project can be at risk.

The following actions are found to be helpful to produce business process description serving as a communication tool:

1. Structured approach to the description of the processes is essential, limited amount of time, discussions devoted to the single process description. Limited time frame and structured approach are identified as significant influencing factors in the creation of understandable business process model in the theoretical research [3].

2. Very clear criteria should be kept in mind to select the business processes to be described to avoid the description of the $100 \%$ of cases. The most frequently practically used criteria might be different for different projects. For the purposes of process optimisation the criteria should be: (1) the most resource, time consuming processes, (2) the highest number of quality issues requiring resources for rework etc. For the IS implementation purposes the criteria should be: (1) the business processes, where the automation and new technologies will bring the most value for the business; (2) the most intensive 6 - 7 information flows out of 10 etc.

The actions mentioned above should be planned and monitored continuously by the manager of the business analysts' team or senior business analyst. The drawbacks from limiting business process modelling scope, schedule and discussions around the model are (1) the risk of building incomplete model; (2) limited use of automated tools for business process analysis, for instance, described in [4] and [5].

Business process modelling as a part of the project doesn't add any value for the business directly, i.e. the result is not implemented change, an automated information flow or any other tangible result. However, business process modelling is time and resource consuming phenomena. Business analysts often face pressure from the businesses to skip the description of the 'as-is' processes and concentrate on the 'tobe' processes only to cut costs for the analysis and produce the tangible results faster. In addition, the description of the 'as-is' processes is more time consuming and complex as the knowledge stays with the business people primary and not with the business analysts (for 'to-be' processes the situation is vice versa). In our practice, the projects skipping the 'as-is' processes description do not bring the results faster. The time and analysts' resources saved are used later by the analysts' team or business management to argue the feasibility of the changes proposed, e.g., to discuss 'it cannot be done like this' arguments from the people involved in the existing processes. Hence, the task of the manager of the business analysts' team is to insist on the description of the existing business processes at the beginning always.

The third challenge is to find the right business analysts' team for the particular project. The team is essential, because the ability to identify the right level of detail of the process description, obtaining the right information from business people involved in the process depends on the soft skills of the team and every individual analyst. The team must know the notation used, the tool and the principles of the modelling. However, the successful team should have business (industry) specific knowledge, 
information management techniques, pros and cons of technologies for accessing information (mobile technologies, clouds etc.). The requirements from the business towards the business analysts have changed significantly over the years.

\section{$4 \quad$ Changing Paradigm}

Regardless the primary objective of the project involving process modelling, companies are always looking at the optimisation opportunities to improve the overall company's performance. The most of the companies from our practice have done business process modelling more than once during the 10 years period, they are optimising business processes continuously as well. The optimisation opportunities originating from business processes have decreased, because (1) business people are more connected with other professionals, the knowledge about industry specific issues/solutions is more accessible; (2) off-shelf operational templates are available together with proven implementation approaches, [7]; (3) the best industry practices are built into ERP systems; (4) more and more tools are produced and available on the Internet providing search engines in unstructured data, hence, the businesses can skip sophisticated changes in their processes producing structured data for decision making.

The process optimisation has become one minor part of the improvement of the overall company's performance. According to my experience, the components of overall company's performance improvement are given in the Figure 5. The five components are closely interrelated and should be considered together. For example, to redefine business processes and technologies, an organization should consider which talent requirements are necessary to implement new processes or systems.

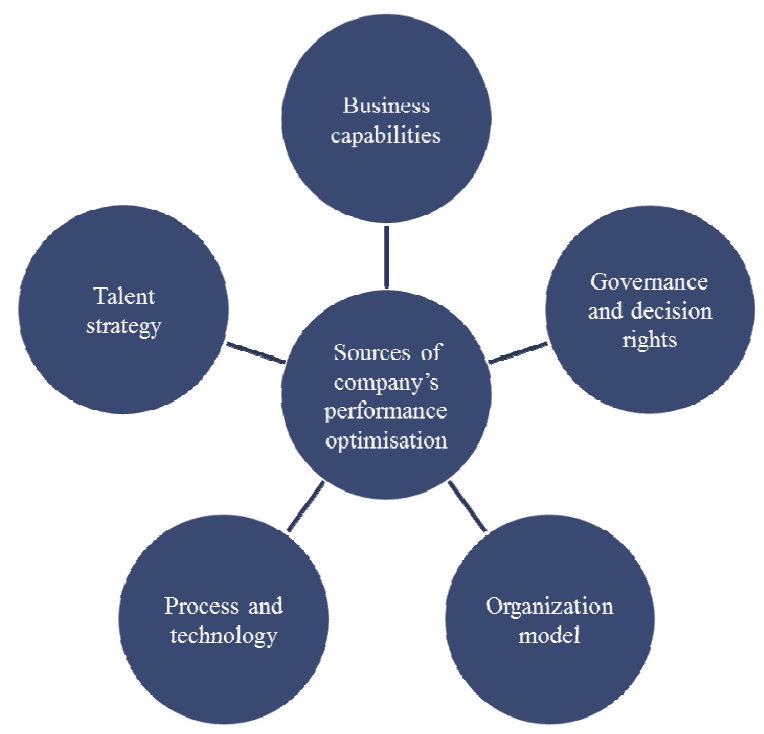

Fig. 5. Sources of company's performance optimisation 
Business capabilities refer to company's core capabilities like relationship management, product design, data analytics required to execute the business. Noncore capabilities can be sourced from external service providers in line with strategic business requirements. Decision rights refer to the codification of business decisions and the accountable decision-making groups/individuals. The organization model includes two elements (1) service delivery that determines choices of location, the organization of the service delivery and (2) the functional groupings, reporting structure, target headcount, and functional responsibilities for each function. Talent strategy includes effective management of the overall talent lifecycle, such as workforce planning, recruitment, on-boarding, development, and performance management.

At the same time business process modelling serves as a backbone, where all the weak performance issues come up and the team of business analysts should be able to propose the most convenient and effective options to the business regardless the area of performance optimisation. This new role requires the wide range of new knowledge for business analysts. Now the good business analyst should be able to ensure the process, where information lands in the hands of the decision maker at the point of the decision. Hence, the methodological knowledge about business process management is not enough. He/she should understand (1) the opportunities provided by mobile technologies, cloud computing for timely information delivery; (2) best practices of the organisation structures and business processes for accounting, IT management, sales etc.; (3) best practices of keeping balance between in-house and outsource functions; (4) best practices of building effective control environment; (5) frameworks of obtaining information for decision making from social networks or other unstructured sources, for instance described in the [8], [9] etc. The new business analyst should be able to put the practices mentioned above in the context of the business and convince the business representatives about the benefits.

\section{Conclusions}

The demand from the business for business process modelling has been high and stable for years. It will remain so in the future as well, because the business is changing continuously due to availability of new technologies.

The key challenges in the business process modelling are (1) keeping the model understandable and complete; (2) finding the right business analysts' team suiting the best the objectives of the modelling. The solutions for the abovementioned challenges lay primarily in the management of the projects, ensuring continuous dialog with the business rather than in using advanced modelling tools and techniques.

The objectives and nature of the modelling process has changed significantly over the last ten years. Initially business analysts were expected to identify the company's performance optimisation opportunities by use of information technologies. Now the business analysts are expected to advise on the benefits of the wide range of information technologies as well as on the best practices of organisation structures, 
business capabilities, talent management etc. All these areas should be put in the context of the company's business to produce the process, where information lands in the hands of the decision maker at the point of the decision.

\section{References}

1. PwC analysis based on webinar survey results. How Financial Services companies can execute the right people strategy (2011)

2. Object Management Group, Business Process Model and Notation (2013), http: / /www. bpmn. org

3. Claes, J., et al.: Tying Process Model Quality to the Modeling Process: The Impact of Structuring, Movement, and Speed. In: Barros, A., Gal, A., Kindler, E. (eds.) BPM 2012. LNCS, vol. 7481, pp. 33-48. Springer, Heidelberg (2012)

4. Accorsi, R., Lehmann, A.: Automatic Information Flow Analysis of Business Process Models. In: Barros, A., Gal, A., Kindler, E. (eds.) BPM 2012. LNCS, vol. 7481, pp. 172-187. Springer, Heidelberg (2012)

5. Ramezani, E., Fahland, D., van der Aalst, W.M.P.: Where Did I Misbehave? Diagnostic Information in Compliance Checking. In: Barros, A., Gal, A., Kindler, E. (eds.) BPM 2012. LNCS, vol. 7481, pp. 262-278. Springer, Heidelberg (2012)

6. Handfield, R.: Best Practices in the Procure-to-Pay Cycle: Perspectives from Suppliers and Industry Experts (2013), http: / / www . supplychainredesign.com/ publications/practix032006.pdf

7. Buchmann, A., Appel, S., Freudenreich, T., Frischbier, S., Guerrero, P.E.: From Calls to Events: Architecting Future BPM Systems. In: Barros, A., Gal, A., Kindler, E. (eds.) BPM 2012. LNCS, vol. 7481, pp. 17-32. Springer, Heidelberg (2012)

8. Scekic, O., Truong, H.-L., Dustdar, S.: Modeling Rewards and Incentive Mechanisms for Social BPM. In: Barros, A., Gal, A., Kindler, E. (eds.) BPM 2012. LNCS, vol. 7481, pp. 150-155. Springer, Heidelberg (2012) 